\title{
Spall through void nucleation, growth and coalescence
}

\author{
M.J. Worswick, H. Nahme* and J. Fowler \\ Department of Mechanical and Aerospace Engineering, Carleton University, Ottawa Ontario, Canada, \\ KIA $5 B 6$ \\ * Ernst-Mach-Institut, Eckerstrasse 4, 7800 Freiburg, Germany
}

\begin{abstract}
Resumé: Des expériences de chargement dynamique par projection de plaques ont été effectuées à des vitesses entre 53 et $256 \mathrm{~m} / \mathrm{s}$ sur du laiton contenant des particules de plomb pour étudier le processus de rupture ductile à des taux élevés de de déformation. Les particules de plomb dispersées dans le métal agissent comme site de nucléation favorisant la rupture ductile par les mécanismes de nucléation, croissance et jonction des vides. De l'écaillage a été observé pour des vitesses d'impact supérieures à $120 \mathrm{~m} / \mathrm{s}$. Les mesures de vitesses de la surface libre des plaques cibles ont été effectuées à l'aide d'un VISAR et elles ont servi à valider un modèle de rupture ductile basé sur la fonction d'écrouissage de Gurson [1] qui a été implémenté dans le code hydrodynamique LS-DYNA2D. Les résultats prédits par simulation et les valeurs mesurées de vitesse des écailles sont très similaires.
\end{abstract}

\begin{abstract}
Plate impact experiments, in the range $53-256 \mathrm{~m} / \mathrm{s}$, have been performed on leaded brass to study the process of ductile fracture under high rates of strain. The material contains a dispersion of lead particles which serve as void nucleation sites and promote ductile fracture through void nucleation, growth and coalescence. Spall was observed to occur for impact velocities above $120 \mathrm{~m} / \mathrm{s}$. Recorded free surface velocities from VISAR measurements have been used to assess a model of ductile fracture based on the Gurson [1] yield function implemented within the LS-DYNA2D hydrocode. Good agreement is found between predicted and measured spall velocities.
\end{abstract}

\section{INTRODUCTION}

Ductile fracture occurs in metals undergoing tensile plastic deformation through the nucleation, growth and coalescence of small voids to form cracks. While numerous studies of this process have been undertaken within the quasi-static strain rate regime, the effect of material rate sensitivity and inertia on the rate of void nucleation, growth and coalescence at high strain rates is uncertain.

The current work undertakes to obtain experimental data concerning the damage within materials undergoing ductile fracture at high rates of strain. In particular, measurements of spallation through ductile fracture have been obtained in plate impact specimens of UNS C36000 free cutting brass. This "model" material contains a dispersion of weak lead particles serving as void nucleation sites. Void growth occurs in the experiments during the interaction of pressure release waves originating from the free surfaces of the flyer and target plates which create intense triaxial stress states under strain rate conditions in excess of $10^{4} \mathrm{~s}^{-1}$. 
Flyer plate impact velocities in the range $53-256 \mathrm{~m} / \mathrm{s}$ have been considered. Spallation occurs in experiments above $120 \mathrm{~m} / \mathrm{s}$ which have been used to establish the spall strength of the material based on VISAR free surface velocity measurements. Impacts below this threshold velocity were performed to produce incipient spall or damage layers within which void nucleation and growth takes place but terminates prior to void coalescence and final fracture. These specimens are being examined metallographically as part of ongoing research to determine void growth rates.

Numerical prediction of the damage process has been undertaken based on the Gurson [1] constitutive model. This model is used to predict the evolution of porosity within the plates and to account for the destabilizing influence of porosity on plastic flow. Implementation of this model within the LSDYNA2D [2] hydro-code has been undertaken as part of this work. Similar application of the Gurson model to predict spallation in 6061-T6 Aluminum and ductile fracture in expanding rings has been reported by Fyfe and co-workers [3-5]

\section{MATERIAL}

Figure 1 is an optical micrograph of the material prior to testing. UNS C36000 free cutting brass has a nominal composition of $2.5 \%$ lead which forms a globular particulate phase. Most of the material tested was annealed at $840-850^{\circ} \mathrm{C}$ for two hours to promote spheroidization of the lead phase. For this annealing treatment, the average lead particle size is of the order $5 \mu \mathrm{m}$, the initial particle aspect ratio was near unity, and the in-plane nearest-neighbour particle spacing is approximately $15 \mu \mathrm{m}$. The brass matrix is predominantly alpha phase with small regions of beta phase being present. The average grain size was $50-55 \mu \mathrm{m}$.

A number of UNS C36000 brass specimens were annealed at a lower temperature $\left(600^{\circ} \mathrm{C}\right)$ which resulted in less coarsening and smaller lead particles. Additional specimens were fabricated using MS58 brass in an unannealed state. The current paper, however, considers only spall predictions for the material annealed at $840-850^{\circ} \mathrm{C}$.

\section{EXPERIMENTS}

A detailed description of the experimental procedures can be found in a companion paper, also appearing in these proceedings [6]. Figure 2 is a simplified schematic showing the flyer and target plates. As shown in the figure, the $3 \mathrm{~mm}$ flyer plate impacts the target at a velocity, $v_{0}$. The interaction of pressure release waves originating from the free surfaces of the flyer and target plates after impact results in the formation of a damage or spall layer located $3 \mathrm{~mm}$ from the free surface of the target plate. If the incident velocity is sufficiently high, in this case $v_{0}>120 \mathrm{~m} / \mathrm{s}$, the damage layer will fracture and a spall layer will be ejected at velocity $v_{\text {spall. }}$. Using the approach of Cochran and Banner [7], the difference, $\left(\Delta v_{\text {spall }}\right)$, between the incident velocity of the flyer plate and the velocity of the ejected spall layer will depend upon the material dynamic strength, expressed approximately as

$$
\sigma_{\text {spall }}=\rho c_{l} \Delta v_{\text {spall }} / 2 \text {, }
$$

in which $\sigma_{\text {spall }}$ is known as the material spall strength, $\rho$ is the density, and $c_{l}$ is the longitudinal sound speed. VISAR measurements have been used to record the velocity of the free surface of the target plate from which $\Delta v_{\text {spall }}$ and $\sigma_{\text {spall }}$ have been determined.

\section{MODEL}

The plates and impact were modelled as axi-symmetric using a version of LS-DYNA2D [2] modified by Worswick [8] to incorporate a Gurson-based constitutive model. This code employs explicit time integration with inherent small time steps suitable for tracking the stress wave propagation occurring within the impacting cylinders. 


\subsection{Constitutive Model}

The elastic response of the material was modelled using Hooke's Law for a linear elastic isotropic material. The macroscopic plastic response was modelled using the Gurson[1] constitutive model for porous continuum plastic materials as modified by Tvergaard and Needleman[9]. Central to this model is the use of the Gurson yield function to determine the macroscopic stresses, $\Sigma_{i j}$, required to initiate or sustain plastic flow within a plastically dilating porous solid:

$$
\phi=\left(\frac{\Sigma_{e q}}{\bar{\sigma}}\right)^{2}+2 f^{*} q_{1} \cosh \left(q_{2} \frac{3 \Sigma_{h y d}}{2 \bar{\sigma}}\right)-1-q_{3} f^{* 2}=0,
$$

in which $\Sigma_{e q}$ is the equivalent stress, defined by $\Sigma_{e q}^{2}=3 / 2 \Sigma_{i j}^{\prime} \Sigma_{i j}^{\prime}$, with $\Sigma_{i j}^{\prime}$ being the deviatoric components of $\Sigma_{i j}$ and $\Sigma_{h y d}$ is the hydrostatic component of stress, given by $\Sigma_{h y d}=1 / 3 \Sigma_{k k}$. The coefficients $q_{1}, q_{2}$ and $q_{3}$ are "calibration" coefficients introduced by Tvergaard [10] to better represent the effects of porosity in plastically deforming materials. The values adopted were $q_{1}=1.25, q_{2}=$ 0.95 and $q_{3}=q_{1}^{2}$, given by Worswick and Pick [11].

$f^{*}$ is initially equal to the void volume fraction, $f$, but is modified to account for the onset of void coalescence according to the following function proposed by Tvergaard and Needleman [9]:

$$
f^{*}= \begin{cases}f & \text { if } f \leq f_{c} \\ f_{c}+\frac{f_{u}^{*}-f_{c}}{f_{f}-f_{c}}\left(f-f_{c}\right) & \text { if } f \geq f_{c} .\end{cases}
$$

Following Tvergaard and Needleman [9], $f_{c}$ is the critical value of porosity at which void coalescence commences. To simulate the effect of void coalescence and the resultant loss of material strength, void growth is accelerated once the porosity exceeds this level according to equation (3). Coalescence is assumed to be complete once $f$ reaches a final critical value, $f_{f}$, and the material strength vanishes according to equations (2) and (3) with $f_{u}^{*}=1 / q_{1}$.

Using equation (2) as a flow potential and applying the normality condition [1], one obtains constitutive equations relating the macroscopic stress and strain rates,

$$
\dot{\Sigma}_{i j}=C_{i j k l} \dot{\epsilon}_{k l}^{\infty},
$$

the details of which are given in [8].

The rate of increase in porosity will be due to the growth of existing voids and the nucleation of new voids,

$$
\dot{f}=\dot{f}_{\text {growth }}+\dot{f}_{\text {nucleation }}
$$

The growth of existing voids is given by

$$
\dot{f}_{\text {growth }}=(1-f) \dot{\epsilon}_{k k}^{p \infty},
$$

since the matrix material is assumed to be incompressible and $\dot{\epsilon}_{k k}^{p \infty}$ is due purely to void expansion. Void nucleation is modelled as plastic strain-controlled. It is assumed that voids nucleate at second phase particles and that there will be a statistical variation in the nucleation strain for individual particles. Assuming that the nucleation strain for the total population of particles follows a normal distribution, one can use the following equation adopted by Gurson [1]:

$$
\dot{f}_{\text {nucleation }}=A h \dot{\bar{\epsilon}}^{p},
$$

where

$$
A=\frac{1}{h} \frac{f_{N}}{S_{N} \sqrt{2 \pi}} \exp \left[-\frac{1}{2}\left(\frac{\bar{\epsilon}^{p}-\epsilon_{N}}{S_{N}}\right)^{2}\right] .
$$

The term $f_{N}$ represents the volume fraction of void nucleating particles while $\epsilon_{N}$ and $S_{N}$ are the average and standard deviation of the strains at which the particles nucleate voids. In free cutting brass, the globular lead phase would constitute the void nucleating particles. 
Equations (2) through (8) combine to describe a constitutive model for the evolution of porosity during plastic deformation and the reduction in material load-carrying capacity, referred to as constitutive softening. This set of equations was implemented as a Gurson constitutive routine in LS-DYNA2D. Details of the numerical integration scheme used to integrate these equations are given in [8].

\subsection{Finite Element Model}

Figure 3 shows the axi-symmetric finite element mesh used to model the flyer and target plates. The plate dimensions are given in Figure 2. Contact boundary conditions, known as slide lines were used to model the intermittent contact between the flyer and target. The target plate was modelled as initially at rest while the flyer was assigned an initial impact velocity equal to that considered in the experiment.

\section{RESULTS}

Detailed discussion of the spall strengths for all of the materials tested are given by Nahme and Worswick [6]. The failure mode was confirmed to be ductile fracture as observed in Figure 4 which shows an arrested crack tip within a plate impacted at $133 \mathrm{~m} / \mathrm{s}$.

Figure 5 plots the recorded free surface velocity time histories from six of the UNS C36000 plates annealed for two hours at $840-850^{\circ} \mathrm{C}$. Spall occured for the plates impacted at velocities above $133 \mathrm{~m} / \mathrm{s}$. Also plotted in the figure are the predicted velocities from the corresponding finite element calculations (symbols). The agreement in the predicted spall velocity, given by the dip or pull back of the velocity history, is quite good. For example, the decrease in free surface velocity for the plate impacted at $175 \mathrm{~m} / \mathrm{s}$ was roughly $45 \mathrm{~m} / \mathrm{s}$ compared to the model prediction of $40 \mathrm{~m} / \mathrm{s}$. This level of agreement is encouraging since the spall velocity predicted by the model is based on the yield surface limitation of stress and on the void coalescence criterion.

Finite element predictions of damage and spall are shown in Figures 6 and 7 for impact velocities of 86 and $175 \mathrm{~m} / \mathrm{s}$, respectively. In Figure 6 , the impact velocity was insufficient to produce enough damage to cause final fracture. An incipient spall layer did form, however, as indicated by the band of high void volume fraction located roughly $3 \mathrm{~mm}$ from the free surface. For the higher impact velocities, the extent of void growth was sufficient to predict void linkage according to Equation 3 as observed in Figure 7.

The predicted stress state, strain rate and void growth histories within the centre of the damage layer are plotted in Figures 8-10. Plotted in Figure 8 is the triaxiality, $\Sigma_{h y d} / \bar{\sigma}$, for impact velocites of 86 and $175 \mathrm{~m} / \mathrm{s}$. Figures 9 and 10 show the predicted strain rate $\left(\log _{10} \dot{\epsilon}\right)$ and void growth for the same impact velocities. The triaxiality is initially compressive and large until the release waves converge at the damage layer roughly $3 \mu \mathrm{s}$ after impact. At this point, the triaxiality increases and reaches peak values of $3-5$. During this period of intense tensile triaxiality, the strain rate is roughly $10^{4}-10^{5} \mathrm{~s}^{-1}$ and extremely rapid void growth results, as seen in Figures 9 and 10. For the higher impact velocity, the condition, $f=0.25$, for element failure is reached and the time history ends at this point. Damage accumulation occurs during the period $3-5 \mu$ s for the $86 \mathrm{~m} / \mathrm{s}$ impact velocity. A rapid decrease in triaxiality is observed during this period of void growth due to a contraction of the yield surface as porosity increases.

\section{SUMMARY AND FUTURE WORK}

The comparison between the predicted and measured free surface velocity histories shows good agreement. Further investigation is necessary, concerning the sensitivity of the predictions to a number of the parameters contained in the model such as the critical porosity levels to cause void coalescence (Equation 3) as well as the element size. 
Detailed metallurgical measurement of the extent of void growth in the specimens impacted below the threshold for spallation is underway in order to assess the predicted void growth rates obtained using the model. The conditions leading to void coalescence in the brass specimens subjected to different heat treatments will also be considered in order to examine the effect of different lead particle population morphologies on coalescence.

\section{References}

1. Gurson A.L., Plastic Flow and Fracture of Ductile Materials Incorporating Void Nucleation, Growth and Interaction, Ph.D. Thesis, Brown University, 1975.

2. Hallquist H.O. LS-DYNA2D An Explicit Two-Dimensional Hydrodynamic Finite Element Code with Interactive Rezoning and Graphical Display, Livermore Software Technology Corp., April, 1990.

3. Rajendran, A.M. and Fyfe, I.M., J. Applied Mech., 49 (1982) 31.

4. Fyfe, I.M., in Material Behaviour under High Stress and Ultra High Loading Rates, ed. J. Mescall and V. Weiss, Plenum, NY, 1982, 309.

5. Fyfe, I.M. and Choi, S.R., in Macro- and Micro-Mechanics of High Velocity Deformations and Fracture, Ed. K. Kawata, Springer-Verlag, 1986.

6. Nahme H. and Worswick M.J., Dynamic Properties and Spall Plane Formation of Brass, also appearing in these proceedings.

7. Cochran and Banner, J. Applied Physics 48, (1972) 2729.

8. Worswick M.J., paper to be submitted to I.J. Num. Meth. Engng. (1994)

9. Tvergaard V. and Needleman A., Acta Met. 32 (1984) 157.

10. Tvergaard V., Int. J. Frac. 17, (1981) 389.

11. Worswick M.J. and Pick R.J., J. Appl. Mech. 58 (1991) 631.

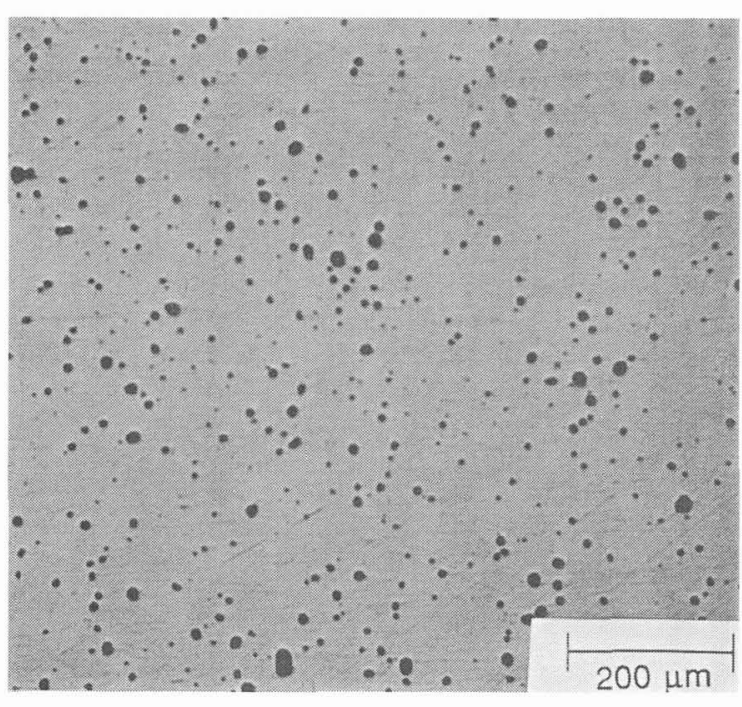

Figure 1: Optical micrograph of UNS C36000 free cutting brass annealed at $850^{\circ} \mathrm{C}$ for 2 hours. Polished only.
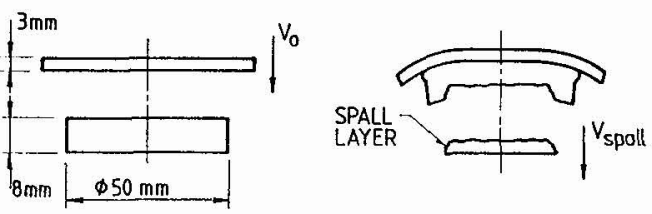

Figure 2: Schematic of flyer-plate impact before (left) and after (right) impact.

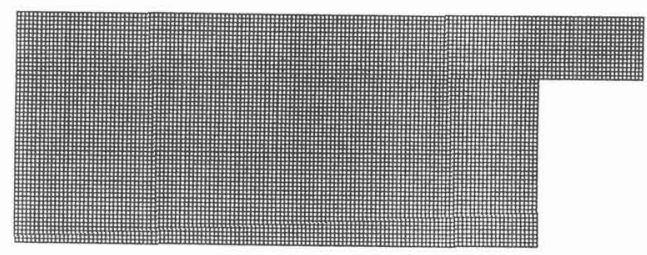

Figure 3: Finite element mesh used to model the flyer and target plates. 


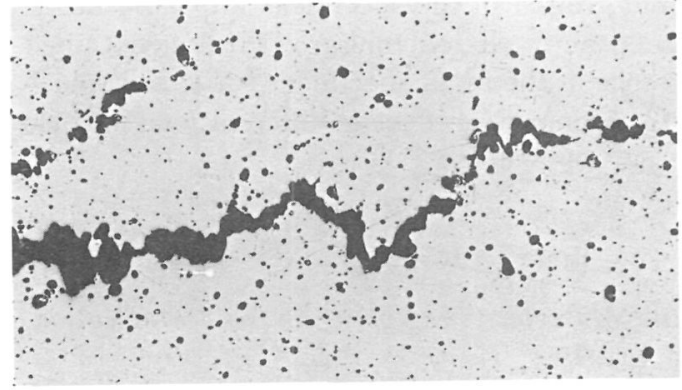

Figure 4: Optical micrograph taken near the crack tip within the spall plane of the plate impacted at $133 \mathrm{~m} / \mathrm{s}$. Polished only.

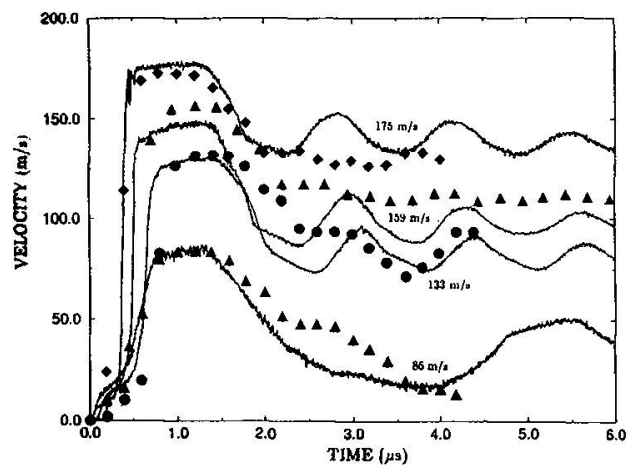

Figure 5: Measured (solid lines) and predicted (dashed lines) free surface velocities from target plates of UNS C36000 free cutting brass annealed at $840-850^{\circ} \mathrm{C}$ for two hours. Impact velocities are indicated.

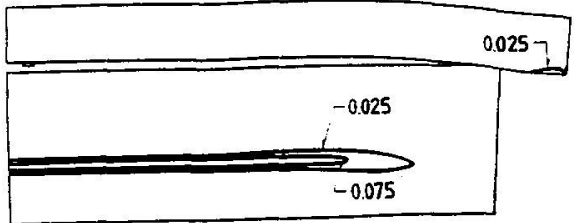

Figure 6: Contours of void volume fraction predicted for a plate impact of $86 \mathrm{~m} / \mathrm{s}$.

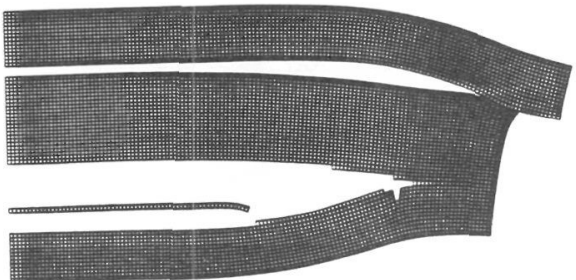

Figure 7: Deformed finite element mesh showing spallation after impact at $175 \mathrm{~m} / \mathrm{s}$.

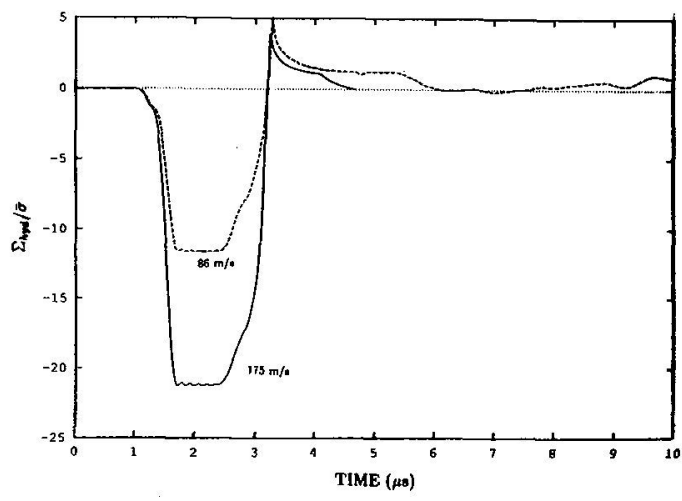

Figure 8: Time histories of triaxiality from an element located at the centre of the damage layer for impact velocities of 86 and $175 \mathrm{~m} / \mathrm{s}$.

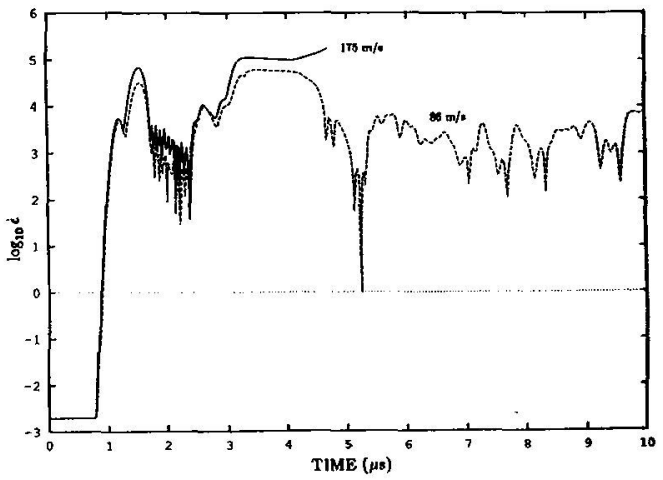

Figure 9: Time histories of strain rate from an element located at the centre of the damage layer for impact velocities of 86 and $175 \mathrm{~m} / \mathrm{s}$.

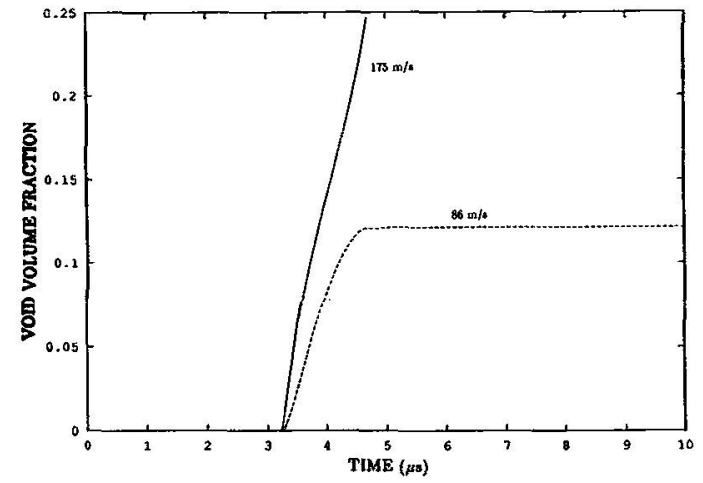

Figure 10: Time histories of void volume fraction from an element located at the centre of the damage layer for impact velocities of 86 and $175 \mathrm{~m} / \mathrm{s}$. 